\title{
New 5-LOX and 15-LOX Inhibitors Isolated from Red Sea Derived Brown Alga Sarragassum Cinnerum: An In Silico-Supported Study
}

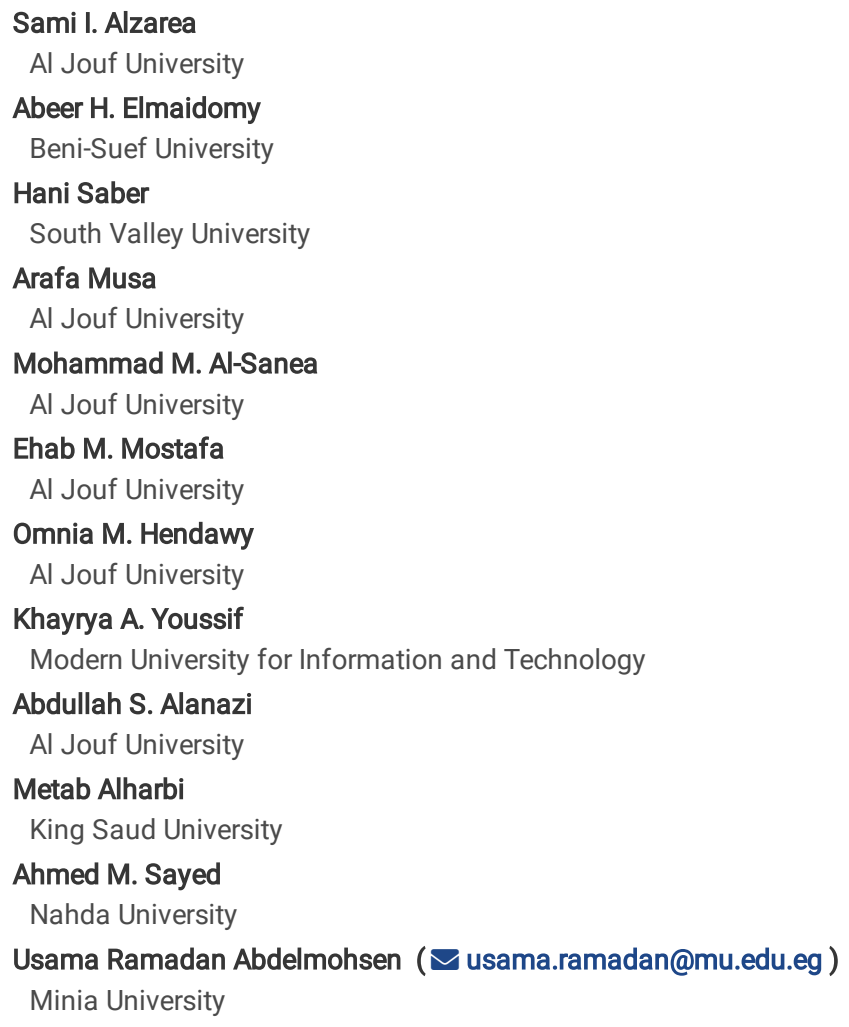




\section{Abstract}

Sargassum is a brown algal genus inhabiting tropical region. Metabolomic profiling of Sarragassum cinnerum "Sargassaceae", dereplicated eleven compounds 1-11, further phytochemical investigation afforded two new aryl cresol 12-13, along with eight known compounds 14-21. Both new metabolites along with 19 showed moderate in vitro antiproliferative activity against HEPG2, MCF7, and CACO2. Molecular targets of the bioactive compounds using a pharmacophore-based virtual screening, predicts 5-LOX and 15-LOX as the most probable target linked to their observed antiproliferative activity. The validation step revealed 12 and $\mathbf{1 3}$ inhibited 5-LOX more prudentially than 15-LOX, while 19 showed a convergent inhibitory activity toward both enzymes. Further in-depth in silico analysis revealed the molecular interactions inside both enzymes active sites and explained the varying inhibitory activity for $\mathbf{1 2}$, and 13 toward 5-LOX and 15-LOX. Taken together, unique metabolites in S. cinnerum had potential anticancer activity supported with in-silico investigations to facility drug discovery and development processes.

\section{Introduction}

Worldwide, the macro-algal genus Sargassum C. Agardh (1820) includes over 537 species, as well as 426 infra-specific names in the database ${ }^{1}$. At present, 361 of the species names have been flagged as accepted taxonomically based on the record literature under the species name ${ }^{1}$. Sargassum is a cosmopolitan brown algal genus, inhabiting temperate subtropical and tropical marine environments, which is identified by non-filamentous thallus with a holdfast that arms to form many central axes ${ }^{2}$. They have specific leaves, receptacles, and the vesicles which are located on the axes near the leaves hold the algal structure upright when submerged ${ }^{3}$.

Sargassum species are nutritious and valuable source of bioactive compounds like vitamins, carotenoids, dietary fibers, proteins, and minerals ${ }^{4}$. Additionally, many biologically active compounds such as terpenoids, flavonoids, sterols, sulfated polysaccharides, polyphenols, sargaquinoic acids, sargachromenol, pheophytine were separated from different Sargassum species ${ }^{4}$. These isolated compounds exhibit distinct biological activities like analgesic, antiinflammatory, antioxidant, neuroprotective, anti-microbial, anti-tumor, fibrinolytic, immune-modulatory, anti-coagulant, hepatoprotective, anti-viral activity. Therefore, Sargassum species have considerable potential to be utilized in pharmaceutical and nutraceutical areas ${ }^{4,5}$.

According to literature, eicosanoids was formed from arachidonic acid (AA) oxidation cascade; which have been linked to pathogenesis for number of human diseases including cancer. Nowadays; there is enough evidence supporting their part in tumorigenesis and metastases ${ }^{6-9}$.

Although most consideration has focused on prostaglandins (PGs) and other cyclooxygenase (COX) derived metabolites. There is growing evidence suggests that lipoxygenase (LOXs) catalyzed products, such as leukotrienes (LTs), have also profound biological effects on the progression of human cancers ${ }^{6-9}$.

LOXs are a family of non-heme iron-containing enzymes; that catalyze the oxygenation of polyunsaturated fatty acids ${ }^{9}$. Several later records on the relation between LOXs and cancer development support a critical role for 5-lipoxygenase (5-LOX) and 15-lipoxygenase (15-LOX) during the initial stages of prostate, colorectal and pancreatic carcinogenesis ${ }^{6,8}$. Consequently; using LOXs inhibitors has a vital effect on reducing the growth of these tumor cells ${ }^{6,8}$.

In the present study, metabolomic profiling and phytochemical investigation of $S$. cinnerum were investigated using liquid chromatography high resolution mass spectrometry (LC-HRESIMS), chromatographic, and spectroscopic techniques. The antiproliferative activity of the isolated compounds was in vitro tested on breast Michigan Cancer Foundation-7 (MCF-7), hepatic G2 (HepG2), and colorectal adenocarcinoma-2 (CACO2) cancer cell lines. Since LOXs have a role in viability of tumor cells $\mathbf{s}^{6,8}$, several isolated compounds were assayed for their 5-LOX and 15-LOX inhibitory activities. Docking and dynamic studies were conducted to determine the interactions of these compounds inside the enzymes active sites.

\section{Results And Discussion}

\section{Chemical Dereplication of Sarragassum cinnerum}

Metabolomic profiling of S. cinnerum crude extract, dereplicated eleven compounds, using LC-HRESIMS. The identified metabolites 1-11 belonged to different chemical classes, including tetrahydrofuran, hydroquinone, plastoquinone, sterols, meroditerpenoids, and sulfoglycolipid (Supplementary Table S1, Figures S12, Figure1)

Analyzing of $S$. cinnerum crude extract, several hits were proposed (Supplementary Table S1, Figure S1-2, Figure1). The molecular ion mass peaks at $m / z$ 215.1283, and 277.2162 [M-H]+, for the predicted molecular formulas $\mathrm{C}_{11} \mathrm{H}_{20} \mathrm{O}_{4}$ and $\mathrm{C}_{18} \mathrm{H}_{30} \mathrm{O}_{2}$ gave hits of the tetrahydrofuran antibacterial, and bisnorditerpenes type cytotoxicity against P388 cells (5R,7S,8S)-Communiol A 1, and Hedaol A 2, respectively, that were previously isolated from Sargassum spp. ${ }^{10,11}$. The mass ion peaks at $m / z 307.2624$, and 343.2276 corresponding to the suggested molecular formulas $\mathrm{C}_{20} \mathrm{H}_{34} \mathrm{O}_{2}$, and $\mathrm{C}_{22} \mathrm{H}_{30} \mathrm{O}_{3}[\mathrm{M}+\mathrm{H}]+$ fit a fatty acid, and hydroquinone anti-inflammatory derivative compound Arachidonic acid 3, and Sargachromanol A 4, that was previously isolated from Sargassum pallidum, and Sargassum siliquastrum, respectively ${ }^{12,13}$. The ion mass peaks at $\mathrm{m} / \mathrm{z} 395.2950,425.3420,427.3576$, and $487.3060[\mathrm{M}+\mathrm{H}]+\mathrm{for}$ the predicted molecular formulas $\mathrm{C}_{27} \mathrm{H}_{38} \mathrm{O}_{2}, \mathrm{C}_{29} \mathrm{H}_{44} \mathrm{O}_{2}, \mathrm{C}_{29} \mathrm{H}_{46} \mathrm{O}_{2}$, and $\mathrm{C}_{29} \mathrm{H}_{42} \mathrm{O}_{6}$ gave hits of the antiviral plastoquinones 2-Geranylgeranyl-6-methylbenzoquinone 5, which was isolated from Sargassum micracanthum ${ }^{14}$, the anticancer steroidal nucleus of 24-Ethylcholesta-4,24(28)-dien-3,6-dione 6, Saringosterone 7, which were isolated from Sargassum carpophyllum, and Sargassum asperfolium, respectively ${ }^{15,16}$, and the antioxidant meroditerpenoids of Nahocol A 8 , which were isolated from Sargassum siliquastrum ${ }^{17}$. Two major ion peaks with the $\mathrm{m} / \mathrm{z}$ values of 445.3682 and 459.2749 [M+H]+ with molecular formulas $\mathrm{C}_{29} \mathrm{H}_{48} \mathrm{O}_{3}$ and $\mathrm{C}_{27} \mathrm{H}_{38} \mathrm{O}_{6}$ were detected and dereplicated as 24xi-Hydroperoxy-24-vinylcholesterol 9, and Sargathunbergol A 10, respectively, which were isolated earlier from Sargassum carpophyllum, and Sargassum thunbergii, respectively ${ }^{15,18}$. 
In addition, the mass ion peaks at $\mathrm{m} / \mathrm{z} 553.2681[\mathrm{M}-\mathrm{H}]+$, for the predicted molecular formula $\mathrm{C}_{25} \mathrm{H}_{46} \mathrm{O}_{11} \mathrm{~S}$ was dereplicated sulfoglycolipid derivative 1-O-(11Hexadecenoyl)-3-O-(6'-sulfo- $\alpha$-D-quinovopyranosyl) glycerol 11, which was previously detected in Sargassum hemiphyllum (Figure1) ${ }^{19}$.

\section{Phytochemical investigation of Sarragassum cinnerum}

Based on the physicochemical and chromatographic properties, the spectral analyses from UV, ${ }^{1} \mathrm{H}$, and DEPT-Q NMR, as well as comparisons with the literature and some authentic samples, the crude methanolic extract of $S$. cinnerum afforded the new aryl cresol 12-13, along with the known 0 -Cresol $14^{20}$, $m$-Cresol $15^{21}$. Additionally, arachidonic acid $16^{22}$, eicosenoic acid $17^{22}, 1$-O-arachidonyl-glycerol $18^{23}, 1$ - $O$-arachidonyl-3-O-( $\alpha$-D-glucopyranosyl) glycerol $19^{23}$, 7- $\beta$-methyl androsterol $\mathbf{2 0} \mathbf{2}^{24}$, and 1-deoxy- $\beta$-D-psicosofuranose $\mathbf{2 1} \mathbf{1}^{25}$, were identified (Figure 2 ). All characterized compounds $\mathbf{1 4}$, and $\mathbf{1 5}$ were isolated herein for the first time from the genus Sarragassum (Figures S3-28, Figure 2).

Analysis of the HRESIMS, 1D and 2D NMR data of compounds 12-13 suggested a possible plastoquinones core scaffold ${ }^{11}$. The HRESIMS data for compound 12 showed an adduct pseudo-molecular ion peak at $\mathrm{m} / \mathrm{z} 314.2607[\mathrm{M}+\mathrm{H}]^{+}$(calc. for $\mathrm{C}_{22} \mathrm{H}_{34} \mathrm{O}, 314.2604$ ), suggesting 7 degrees of unsaturation. The ${ }^{1} \mathrm{H}$ and DEPT-Q ${ }^{13} \mathrm{C}$ NMR data (Table 1, Figures S3-S4), along with the Heteronuclear Single Quantum Correlation Experiment (HSQC) data (Figure S5), suggested six characteristic resonances appeared: three aromatic methine groups at $\delta_{\mathrm{H}} 6.68(1 \mathrm{H}, \mathrm{s}) \delta_{\mathrm{C}} 91.1, \delta_{\mathrm{H}} 5.18(1 \mathrm{H}, \mathrm{m}) \delta_{\mathrm{C}} 116.0, \delta_{\mathrm{H}} 6.98(1 \mathrm{H}, \mathrm{d}, J=$ $8.0 \delta_{\mathrm{C}} 123.6, \delta_{\mathrm{H}} 7.13(1 \mathrm{H}, \mathrm{d}, J=8.0) \delta_{\mathrm{C}} 123.1$, three quaternary carbons at $\delta_{\mathrm{C}} 153.8,140.6$, and 134.5 , and one methyl group at $\delta_{\mathrm{H}} 1.34(1 \mathrm{H}, \mathrm{s}) \delta_{\mathrm{C}} 29.8$, suggesting the characteristic core structure for a tri-substituted benzene unit ${ }^{11}$.

Table 1. DEPT-Q (400 MHz) and ${ }^{1} \mathrm{H}(100 \mathrm{MHz})$ NMR data of compounds 12,13 in DMSO- $d_{6}$; Carbon multiplicities were determined by the DEPT-Q experiments

\begin{tabular}{|c|c|c|c|c|}
\hline Position & 12 & & 13 & \\
\hline & $\delta_{C}$ & $\delta_{\mathrm{H}}(\mathrm{J}$ in $\mathrm{Hz})$ & $\delta_{C}$ & $\delta_{\mathrm{H}}(\mathrm{J}$ in $\mathrm{Hz})$ \\
\hline 1 & $153.8, \mathrm{qC}$ & & $153.8, \mathrm{qC}$ & \\
\hline 2 & $123.1, \mathrm{CH}$ & $7.13, d(8.0)$ & $123.1, \mathrm{CH}$ & $7.13, d(8.0)$ \\
\hline 3 & $123.6, \mathrm{CH}$ & $6.98, d(8.0)$ & $123.6, \mathrm{CH}$ & $6.98, d(8.0)$ \\
\hline 4 & $134.5, q C$ & & $140.6, q C$ & \\
\hline 5 & $140.6, \mathrm{qC}$ & & $116.0, \mathrm{CH}$ & $6.68, s$ \\
\hline 6 & $116.0, \mathrm{CH}$ & $6.68, s$ & $134.5, \mathrm{qC}$ & \\
\hline 7 & $29.8, \mathrm{CH}_{3}$ & $1.34, s$ & $31.9, \mathrm{CH}_{3}$ & $1.23, s$ \\
\hline $1^{\prime}$ & $33.4, \mathrm{CH}_{2}$ & $2.26, \mathrm{~m}$ & $33.7, \mathrm{CH}_{2}$ & $2.26, \mathrm{~m}$ \\
\hline $2^{\prime}$ & $20.3, \mathrm{CH}_{2}$ & 2.03, overlapped & $20.5, \mathrm{CH}_{2}$ & 2.03, overlapped \\
\hline $3^{\prime}$ & 27.1, $\mathrm{CH}_{2}$ & 2.01 , overlapped & 27.1, $\mathrm{CH}_{2}$ & 2.01, overlapped \\
\hline $4^{\prime}$ & $127.9, \mathrm{CH}$ & $5.31-5.35, m$ & $127.9, \mathrm{CH}$ & $5.31-5.35, m$ \\
\hline $5^{\prime}$ & $128.8, \mathrm{CH}$ & $5.31-5.35, m$ & $128.8, \mathrm{CH}$ & $5.31-5.35, m$ \\
\hline $6^{\prime}$ & $25.5, \mathrm{CH}_{2}$ & 2.78, overlapped & $25.5, \mathrm{CH}_{2}$ & 2.78, overlapped \\
\hline $7^{\prime}$ & $128.0, \mathrm{CH}$ & $5.31-5.35, m$ & $128.1, \mathrm{CH}$ & $5.31-5.35, m$ \\
\hline $8^{\prime}$ & $128.3, \mathrm{CH}$ & $5.31-5.35, m$ & $128.4, \mathrm{CH}$ & 5.31-5.35, $m$ \\
\hline $9^{\prime}$ & 25.6, $\mathrm{CH}_{2}$ & 2.78, overlapped & 25.6, $\mathrm{CH}_{2}$ & 2.78, overlapped \\
\hline 10 & $128.2, \mathrm{CH}$ & 5.31-5.35, $m$ & $128.3, \mathrm{CH}$ & $5.31-5.35, m$ \\
\hline $11^{\prime}$ & $129.4, \mathrm{CH}$ & 5.31-5.35, $m$ & $129.4, \mathrm{CH}$ & 5.31-5.35, $m$ \\
\hline $12^{\prime}$ & $24.9, \mathrm{CH}_{2}$ & 1.52, overlapped & $24.9, \mathrm{CH}_{2}$ & 1.52, overlapped \\
\hline $13^{\prime}$ & $28.9, \mathrm{CH}_{2}$ & 1.24, overlapped & $28.9, \mathrm{CH}_{2}$ & 1.24, overlapped \\
\hline $14^{\prime}$ & $22.4, \mathrm{CH}_{2}$ & 1.25 , overlapped & $22.4, \mathrm{CH}_{2}$ & 1.25 , overlapped \\
\hline $15^{\prime}$ & $14.5, \mathrm{CH}_{3}$ & $0.89, t(6.6)$ & $14.3, \mathrm{CH}_{3}$ & $0.85, t(6.6)$ \\
\hline
\end{tabular}

qC, quaternary, $\mathrm{CH}$, methine, $\mathrm{CH}_{2}$, methylene, $\mathrm{CH}_{3}$, methyl carbons

NMR data also showed eight aliphatic methylene groups at $\delta_{\mathrm{H}} 1.20-2.8 \delta_{\mathrm{C}} 20.5-33.7$ (Table 1$)$, three olefinic methine groups at $\delta_{\mathrm{H}} 5.31-5.35\left(6 \mathrm{H}\right.$, m) $\delta_{\mathrm{C}} 127.9-$ 129.4. These signals are suggestive characteristics for 4,7,11-pentadecenyl moiety, where the Heteronuclear Multiple-Bond Correlation (HMBC) experiment 
of 12 (Figure 3) confirmed the position of the three olefinic methine groups at $4,7,11$ of the alkene side chain. Moreover, HMBC experiment showed the ${ }^{3} J$ $\mathrm{HMBC}$ correlation of the proton $\mathrm{H}-1^{\prime} \delta_{\mathrm{H}} 2.26\left(\delta_{\mathrm{C}} 33.4\right)$ with the quaternary carbonyl carbon $\mathrm{C}-4^{\prime}\left(\delta_{\mathrm{C}} 134.5\right)$. Accordingly, compound 12 was identified as $4-(1-$ (4,7,11-pentadecenyl)-o-cresol.

The molecular formula of compound 13 was identical to that of 12 based on HRESIMS $\left(\mathrm{C}_{22} \mathrm{H}_{34} \mathrm{O}\right)$. The ${ }^{1} \mathrm{H}$ and ${ }^{13} \mathrm{C}$ NMR data was also very close to those of compound 12 for the 4,7,11-pentadecenyl moiety, but differed in the resonated chemical shifts of the aromatic attached methyl group of the core trisubstituted benzene unit (Table 1). Comparing the DEPT-Q ${ }^{13} \mathrm{C}$ NMR data of compound 13 with those of 12 showed a downfield shifting of carbons C-7 $\left(\Delta \delta_{C}+2.1\right)$, compared with those of compound 12 (Table 1). This suggested a positional difference of the location of the aromatic attached methyl group in the tri-substituted benzene unit versus 12 (Table 1, Figure 2, Figures S8-S12). The assignment of the location of the aromatic attached methyl group in 13 was aided by the HMBC experiment. $\mathrm{A}^{3} \mathrm{~J}$-HMBC correlation (Figure 4$)$ of compound 13 proton $\mathrm{H}-7 \delta_{\mathrm{H}} 1.23\left(\delta_{\mathrm{C}} 31.9\right)$ with the quaternary carbonyl carbon $\mathrm{C}-4\left(\delta_{\mathrm{C}} 140.6\right)$ and a ${ }^{4} \mathrm{~J}$-HMBC correlation of the proton $\mathrm{H}-7 \delta_{\mathrm{H}} 1.23\left(\delta_{\mathrm{C}} 31.9\right)$ with the methylene carbon $\mathrm{C}-1^{\prime}\left(\delta_{\mathrm{C}} 33.7\right)$ confirmed the meta-location of aromatic attached methyl group at the cresol moiety. Accordingly, compound 13 was identified as 4-(1-(4,7,11-pentadecenyl)-m-cresol.

\section{Antiproliferative activity of the isolated metabolites}

The isolated compounds 12-21 were in vitro screened for their ability as antiproliferative against hepatic, breast, and colorectal carcinoma cell lines (HEPG2, MCF7, and CACO2, respectively). Results showed that compounds 12,13 , and 19 were able to inhibit the growth of all tested cell lines moderately with $\mathrm{IC}_{50}$ values ranged from $11.2 \pm 0.6$ to $21.6 \pm 1.3 \mu \mathrm{M}$ (Table 2 ).

Table 2. In vitro antiproliferative activity of the isolated compounds $12-21$ expressed as $\mathrm{IC}_{50} \pm(\mathrm{SSEM}) \mu \mathrm{M}$

\begin{tabular}{|llll|}
\hline $\mathrm{IC}_{50}(\mu \mathrm{M})$ & & & \\
\hline Code & HEPG2 & MCF7 & CACO2 \\
\hline 12 & $14.5 \pm 0.8$ & $17.6 \pm 0.9$ & $18.2 \pm 0.7$ \\
13 & $13.1 \pm 1.1$ & $12.7 \pm 1.3$ & $11.2 \pm 0.6$ \\
14 & $>50$ & $>50$ & $>50$ \\
15 & $>50$ & $>50$ & $>50$ \\
16 & $>50$ & $>50$ & $>50$ \\
17 & $>50$ & $>50$ & $>50$ \\
18 & $>50$ & $>50$ & $>50$ \\
19 & $18.5 \pm 1.4$ & $21.6 \pm 1.3$ & $15.7 \pm 0.9$ \\
20 & $>50$ & $>50$ & $>50$ \\
\hline 21 & $>50$ & $>50$ & $>50$ \\
\hline Doxorubicin & $4.2 \pm 0.3$ & $3.8 \pm 0.2$ & $3.4 \pm 0.1$ \\
\hline
\end{tabular}

$I_{50}$ value of compounds against each cancer cell line, which was defined as the concentration $(\mu \mathrm{M})$ that caused a $50 \%$ inhibition of cell growth in vitro, data were expressed as mean \pm SEM $(n=3)$. One-way analysis of variance (ANOVA) followed by Dunnett's test using PASW Statistics ${ }^{\circledR}$ version 18 (Quarry Bay, Hong Kong) was applied. GraphPad Prism software version 6 (La Jolla, CA, USA) was used for statistical calculations. * statistically significant at $p<$ 0.05. Doxorubicin a positive control

\section{Virtual screening-based target identification}

Characterization of the biological target for a certain molecule is a true challenge, however, the continuous development of in silico tools including molecular modeling and virtual screening has significantly improve the success rate of finding suitable molecular targets. Many online target identification platforms are currently available, and their search protocols are either structural based or ligand-based. PharmMapper is one of these online platforms that can screen and suggest the most probable protein targets of a query molecule based on its pharmacophore model ${ }^{26}$. The basic principle of pharmacophore-based screening is that the binding of certain molecules with their protein targets is mainly determined by key pharmacophore maps (i.e. spatial arrangement of structural features). Thus, molecules that their shapes are able to fit with these pharmacophore maps have the highest probability to bind the same protein target. Consequently, PharmMapper was used to propose a proper protein target for compounds 12, 13 and 19. 5-LOX and 15-LOX were found to be the top-scoring hits for these metabolites. In addition, they have a direct link to tumorigenesis ${ }^{8,27-30}$. Consequently, they were selected for further in vitro and in silico validations.

\section{LOX inhibition assay}

To validate the preliminary virtual screening prediction, compounds $\mathbf{1 2 , 1 3}$ and 19 were assayed for their 5 -LOX and 15-LOX inhibitory activities. Interestingly the three compounds achieved potent enzyme inhibition toward 5-LOX ( $\left(\mathrm{C}_{50} 1.3 \pm 0.1\right.$ to $2.1 \pm 0.4 \mu \mathrm{M}$, Table 3). However, their activity against 15 -LOX was weaker, particularly compounds 12 and $13\left(\mathrm{IC}_{50} 25.3 \pm 0.4\right.$ and $23.6 \pm 0.3 \mu \mathrm{M}$, respectively) that were more selective for 5-LOX (Table 3). 
Table 3. Docking scores, binding free energies, $K_{\mathrm{i}}$ and $\mathrm{IC}_{50}$ values of compounds 12,13 , and 19 together with the co-crystalized inhibitors NDGA and AA

\begin{tabular}{|c|c|c|c|c|c|c|c|c|c|c|}
\hline \multirow[t]{2}{*}{ Compound } & \multicolumn{2}{|c|}{$\Delta G_{\text {Vina }}{ }^{*}$} & \multicolumn{2}{|c|}{$\Delta G_{\mathrm{FEP}}{ }^{* *}$} & \multicolumn{2}{|c|}{$\Delta G_{K D E E P}^{* \star *}$} & \multicolumn{2}{|l|}{$K_{\mathrm{i}}{ }^{\#}$} & \multicolumn{2}{|l|}{$\mathrm{IC}_{50} \#$} \\
\hline & 5-LOX & 15-LOX & 5-LOX & 15-LOX & 5-LOX & 15-LOX & 5-LOX & 15-LOX & 5-LOX & 15-LOX \\
\hline 12 & -9.3 & -5.1 & -8.1 & -4.4 & -7.7 & -4.6 & $0.9 \pm 0.1$ & $17.4 \pm 0.2$ & $1.6 \pm 0.3$ & $25.3 \pm 0.4$ \\
\hline 13 & -8.9 & -5.5 & -8.0 & -4.7 & -7.5 & -4.5 & $0.7 \pm 0.2$ & $14.3 \pm 0.4$ & $1.3 \pm 0.1$ & $23.6 \pm 0.3$ \\
\hline 19 & -9.1 & -7.7 & -7.9 & -7.1 & -7.6 & -7.2 & $1.4 \pm 0.2$ & $4.2 \pm 0.1$ & $2.1 \pm 0.4$ & $6.7 \pm 0.3$ \\
\hline $\mathrm{NDGA}^{\# \#}$ & -7.2 & -6.9 & -7.0 & -6.5 & -6.8 & -6.5 & $6.9 \pm 0.1$ & $6.1 \pm 0.2$ & $8.8 \pm 0.3$ & $-9.5 \pm 0.5$ \\
\hline$A A^{\# \#}$ & -7.6 & -7.0 & -6.2 & -6.4 & -7.1 & -6.3 & - & - & - & - \\
\hline
\end{tabular}

Lipoxygenase (LOX), nordihydroguaiaretic acid (NDGA), arachidonic acid (AA)

*Vina docking scores calculated in $\mathrm{kcal} / \mathrm{mol}$

${ }^{* *}$ MDS-derived binding free energies calculated in $\mathrm{kcal} / \mathrm{mol}$ by FEP method

${ }^{* \star *}$ Neural networking-derived binding free energies calculated in $\mathrm{kcal} / \mathrm{mol}$ by KDEEP software

\#In vitro inhibition constant $\left(K_{\mathrm{i}}\right)$ and inhibition concentration $50\left(\mathrm{IC}_{50}\right)$ expressed as $\mu \mathrm{M}$

\# \#The reported co-crystalized ligands

Moreover, they showed inhibitory constants $\left(K_{\mathrm{i}}\right)$ ranged from $0.7 \pm 0.2$ to $17.4 \pm 0.2 \mu \mathrm{M}$ (Table 3$)$, and these values were most agree with the competitive inhibition of both enzymes ${ }^{31}$.

The results of enzyme inhibition assay were also correlated with those of the antiproliferative ones for HepG2 and MCF-7 and CACO2. Surprisingly, overexpression of 5-LOX has been reported in breast, liver and colorectal cancers ${ }^{27-29}$. Also 15-LOX has been reported to be over expressed in a number of tumors like prostate and breast cancers. Hence, these enzymes can be considered promising targets for cancer therapy.

\section{Molecular Docking and dynamic simulation}

5-LOX has a hydrophobic active site ${ }^{9}$, that harbor a catalytic iron $\left(\mathrm{Fe}^{+2}\right)$, and such hydrophobicity is essential to allow efficient binding with the hydrophobic substrate, arachidonic acid (AA) (Figure 2) ${ }^{9}$. Compounds 12, 13, and 19 have extended unsaturated hydrophobic side chains that resemble AA (Figure 5).

Molecular docking experiments revealed that these compounds could bind with the 5-LOX's active site efficiently with binding scores ranged from -8.9 to -9.3 $\mathrm{kcal} / \mathrm{mol}$ (Figure 5), and their bindings were even better than the co-crystalized ligands (Table 3). Additionally, the phenolic moiety of both compounds was involved in H-bonding with HIS-600 similarly to the co-crystallized redox-type inhibitor, nordihydroguaiaretic acid (NDGA) (Figure 5).

Compounds 12 and 13's hydrophobic side chains were able to adapt themselves inside the hydrophobic U-shaped active site, where they took convergent orientations, but slightly different from that of AA (Figure 5). LEU-368, ILE-406, LEU-414, and LEU-607 were the main amino acid residues involved in the hydrophobic interactions with their side chains, while PHE-359, TRP-599, and PRO-569 interacted with their aromatic moieties. The binding mode of compound 19 was quite different, where its polar carbohydrate head interacted with LYS-409, GLN-413, and ILE-673 through four strong hydrogen bonds (< 2.5A), while it's hydrophobic tail interacted with LEU-368, LEU-414, TRP-599, and LEU-607 (Figure 5).

Subsequent Molecular Dynamic Simulation (MDS) experiments (50ns) revealed that the three compounds 12, 13, and 19 were able to stabilize the enzyme's active site.

Compounds 12 and 13's positions remained to change over the first $32.4 \mathrm{~ns}$ (RMSD 3.4A). Afterward, they became stable till the end of the simulation (average RMSD values of 2.67 and 2.59ि, respectively), where their extended hydrocarbon chains became more relaxed and straight (Figure 6). The H-bonds between their phenolic group and HIS-600 remained unchanged throughout the MDS. Starting from 22.6ns, GLN-363's side chain became also involved in Hbonding with the phenolic group of both compounds (Figure 6). Additionally, compound 12's tail remained imbedded inside a hydrophobic pocket consists of the side chains of TRP-147, PHE-151, LEU-368, LEU-373, and LEU-414, while compound 13's tail, settled inside another hydrophobic pocket consists of TRP147, LEU-414, ILE-415, and VAL-433 (Figure 6).

Similarly, the hydrophobic part of compound 19 was compacted at the beginning of MDS, and gradually become more extended till stabilization at $25.4 \mathrm{~ns}$ $($ RMSD $=2.75 \mathrm{~A})$, where PHE-359, PRO-569, and TRP-599 became involved in hydrophobic interactions with the molecule's tail. Furthermore, the side chain of LYS-409 became involved in an additional $\mathrm{H}$-bonding with the molecule's hydrophilic carbohydrate part (Figure 6). Further binding free energy calculations $\left(\triangle \mathrm{G}_{\mathrm{FEP}}\right.$ and $\left.\triangle \mathrm{G}_{\mathrm{KDEEP}}\right)$ revealed that compounds 12,13 , and $19 \mathrm{got}$ higher binding free energy values than that of the co-crystalized ligands (Figure 7 ), and were in good accordance with the in vitro enzyme inhibition (Figure 7). 
On the other hand, docking scores of the three compounds against 15-LOX were significantly lower, particularly for compounds 12 and 13 (Figure 7 ) that showed only hydrophobic interactions (with PHE-184, TYR-185, PHE-365, LEU-374, LEU-415, LEU-419, LEU-420, VAL-603, LEU-609, and LEU-610) inside the enzyme's active site. Upon MDS (Figure 7), both compounds showed unstable positioning inside 15-LOX active site, where the surrounding hydrophobic amino acid residues were able to keep them in position till $\sim 23.4 \mathrm{~ns}$ (RMSD $~ 3.5 \AA$ ). Afterward, their position inside the active site began to change dramatically and their RMSDs reached reach about 7.1 $\AA$ and remained to fluctuate till the end of MDS with gross averages of 8.1 and $7.5 \mathrm{~A}$, respectively over the $50 \mathrm{~ns}$ of simulation. This obvious instability of compounds 11 and 12 reflected on their binding free energies and in vitro inhibitory activities that were significantly lower in comparison with 5-LOX (Figure 7).

Such instability was not the case with compound 19, where the hydrophilic carbohydrate moiety was able to form a network of H-bonds (7 H-bonds) with TYR185, GLN-425, ARG-429, and ASP-602. Furthermore, these hydrophilic interactions remained unchanged over the course of MDS, and thus compound 20's RMSD was at equilibrium ( 2.6ิA) till the end of MDS. Such structural and dynamic information can explain the convergent inhibitory activity of compound 19 against both 5-LOX and 15-LOX (Figure7), and the moderate selective inhibition of 5-LOX by compounds 12 and 13 over 15-LOX.

\section{Materials And Methods}

\section{Algae material}

The marine algae S. cinnerum was collected during January 2020 along the shore of the Red Sea in Hurghada, Egypt. The samples were collected in sterilized polyethylene bags, and kept in an icebox, for transportation to the laboratory. Samples were washed thoroughly with sterile distilled water to remove any associated debris. A voucher specimen (2020-BuPD 55) was deposited at the Department of Pharmacognosy, Faculty of Pharmacy, Beni-Suef University, Egypt.

\section{Chemicals and reagents}

The solvents used in this work included $n$-hexane ( $n$-hex., boiling point b.p. $60-80^{\circ} \mathrm{C}$ ), dichloromethane (DCM), ethyl acetate (EtOAC), $n$-butanol ( $n$-but.), and methanol $(\mathrm{MeOH})$ were purchased from El-Nasr Company for Pharmaceuticals and Chemicals (Egypt). High Performance Liquid Chromatography (HPLC) and deuterated solvents used for chromatographic and spectroscopic analyses were purchased from Sigma-Aldrich (Saint Louis, Missouri, USA), including HPLCmethanol, HPLC-water, HPLC-acetonitrile, deuterium oxide $\left(\mathrm{D}_{2} \mathrm{O}\right)$, methanol $\left(\mathrm{CD}_{3} \mathrm{OD}\right)$, and dimethyl sulfoxide (DMSO- $\left.d_{6}\right)$. Column chromatography $(C C)$ was performed using silica gel 60 (63-200 $\mu \mathrm{m}$, E. Merck, Sigma-Aldrich), and Sephadex LH-20 (0.25-0.1 mm, GE Healthcare, Sigma-Aldrich), while silica gel GF254 for Thin-layer chromatography (TLC) (El-Nasr Company for Pharmaceuticals and Chemicals, Egypt) was employed for vacuum liquid chromatography (VLC). Thin-layer chromatography (TLC) was carried out using pre-coated silica gel 60 GF254 plates (E. Merck, Darmstadt, Germany; $20 \times 20 \mathrm{~cm}, 0.25 \mathrm{~mm}$ in thickness). Spots were visualized by spraying with para-anisaldehyde (PAA) reagent (85: $5: 10: 0.5$ absolute EtOH : sulfuric acid : G.A.A. : para-anisaldehyde), followed by heating at $110{ }^{\circ} \mathrm{C}^{32}$. For the biological study, doxorubicin (Sigma-Aldrich, Germany) was used as a positive control while the HEPG2, MCF7, and CACO2 cancer cell lines were obtained from the American Type Culture Collection (ATCC, Rockville, MD, USA; HPACC, Salisbury, UK) and were routinely subcultured twice per week.

\section{Spectral analyses}

Proton ${ }^{1} \mathrm{H}$ and Distortionless Enhancement by Polarization Transfer-Q (DEPT-Q) ${ }^{13} \mathrm{C}$ NMR spectra were recorded at 400 and $100 \mathrm{MHz}$, respectively. Tetramethylsilane (TMS) was used as an internal standard in deuterium oxide $\left(\mathrm{D}_{2} \mathrm{O}\right)$, methanol $\left(\mathrm{CD}_{3} \mathrm{OD}\right)$, and dimethyl sulfoxide $\left(\mathrm{DMSO}-d_{6}\right)$, using the residual solvent peak $\left(\delta_{\mathrm{H}}=4.78\right),\left(\delta_{\mathrm{H}}=3.34,4.78\right.$ and $\left.\delta_{\mathrm{C}}=49.9\right)$ and $\left(\delta_{\mathrm{H}}=2.50\right.$ and $\left.\delta_{\mathrm{C}}=39.5\right)$ as references, respectively. Measurements were performed on a Bruker Advance III $400 \mathrm{MHz}$ with BBFO Smart Probe and a Bruker $400 \mathrm{MHz}$ EON Nitrogen-Free Magnet (Bruker AG, Billerica, MA, USA). Carbon multiplicities were determined using a DEPT-Q experiment. The ultraviolet radiation (UV) spectrum in methanol was obtained using a Shimadzu UV 2401PC spectrophotometer (Shimadzu Corporation - UV-2401PC/UV-2501PC, Kyoto, Japan). Infrared (IR) spectra were measured using a Jasco FTIR 300E infrared spectrophotometer. HRESIMS data were obtained using an Acquity Ultra Performance Liquid Chromatography system coupled to a Synapt G2 HDMS quadrupole time-of-flight hybrid mass spectrometer (Waters, Milford, MA, USA). HPLC chromatographic separations were conducted using an Agilent 1260 Infinity preparative pump (G1361A), Agilent 1260 diode array detector VL (G1315 D), Agilent 1260 Infinity Thermostand column compartment (G1361 A), Agilent 1260 Infinity preparative autosampler (G2260A) and a YMC-Pack ODS-A A-324 column (i.d. $10 \times 300$ mm, YMC, Kyoto, Japan).

\section{Extraction and fractionation of algae material}

Sarragassum cinnerum $(0.5 \mathrm{~kg})$ were collected and air-dried in the shade for one month. After drying, the brown algae were finely powdered using an OC60B/60B grinding machine (60-120 mesh, Henan, Mainland China). The finely powdered algae was extracted by maceration using $70 \%$ methanol ( $3 \mathrm{~L}, 3 \times$, seven days each) at room temperature, and concentrated under vacuum at $45^{\circ} \mathrm{C}$ using a rotary evaporator (Buchi Rotavapor R-300, Cole-Parmer, Vernon Hills, IL, USA) to afford $75 \mathrm{~g}$ crude extract. The dry extract was suspended in $100 \mathrm{~mL}$ distilled water $\left(\mathrm{H}_{2} \mathrm{O}\right)$, and successively portioned with solvents of different polarities ( $n$-Hex., DCM, EtOAC, and $n$-but.). The organic phase in each step separately evaporated under reduced pressure to afford the corresponding fractions I $(8.0 \mathrm{~g}), \mathrm{II}(1.5 \mathrm{~g})$, III (1.5 g) and IV $(3.0 \mathrm{~g})$, respectively, while the remaining mother liquor was then concentrated down to give the aqueous fraction (V). All resulting fractions were kept at $4{ }^{\circ} \mathrm{C}$ for biological and phytochemical investigations.

\section{Metabolomic Analysis Procedure}

The crude methanolic extract from $S$. cinnerum was prepared at $1 \mathrm{mg} / \mathrm{mL}$ for mass spectrometry analysis. The recovered methanolic extract was subjected to metabolic analysis using LC-HRESIMS according to Abdelmohsen et al. $2014^{33}$. An Acquity Ultra Performance Liquid Chromatography system connected to a 
Synapt G2 HDMS quadrupole time-of-flight hybrid mass spectrometer (Waters, Milford, USA) was used. Positive and negative ESI ionization modes were utilized to carry out the high-resolution mass spectrometry coupled with a spray voltage at $4.5 \mathrm{kV}$, the capillary temperature at $320{ }^{\circ} \mathrm{C}$, and mass range from $m / z$ 150-1500. The MS dataset was processed and data were extracted using MZmine 2.20 based on the established parameters ${ }^{22}$. Mass ion peaks were detected and accompanied by chromatogram builder and chromatogram deconvolution. The local minimum search algorithm was addressed and isotopes were also distinguished via the isotopic peaks of grouper. Missing peaks were displayed using the gap-filling peak finder. An adduct search along with a complex search was carried out. The processed data set was next subjected to molecular formula prediction and peak identification. The positive and negative ionization mode data sets from the respective extract were dereplicated against the DNP (Dictionary of Natural Products) databases.

\section{Isolation and purification of compounds}

Fraction I (8 g) was subjected to normal VLC fractionation using silica gel $\mathrm{GF}_{254}$ (column $6 \times 30 \mathrm{~cm}, 50 \mathrm{~g}$ ). Elution was performed using $n$-hex. : EtOAC gradient mixtures in order of increasing polarities $(0,5,10,15,20,25,30,35,40,45,50,60,80$ and 100\%, 500ml each). The effluents from the column were collected in fractions ( $100 \mathrm{~mL}$ each); and each collected fraction was concentrated and monitored by TLC using the system $n$-hex. : EtOAC $8: 2$ and PAA reagent. Similar fractions were grouped and concentrated under reduced pressure to provide three sub-fractions $\left(\mathrm{I}_{1}-\mathrm{I}_{3}\right)$. Subfraction $\mathrm{II}_{2}(3.0 \mathrm{~g})$ was further fractionated on silica gel $60(100 \times 1 \mathrm{~cm}, 50 \mathrm{~g})$. Elution was performed using $n$-hex. : EtOAC gradient mixtures in the order of increasing polarities $(0,1,2$, $3,4,5,6,7,8,9$ and $10 \%, 1 \mathrm{~L}$ each, FR $\left.3 \mathrm{~mL} \mathrm{~min}{ }^{-1}\right)$, to afford four sub-subfractions $\left(\mathrm{II}_{2-1}-\mathrm{II}_{2-4}\right)$. Sub-subfraction $\|_{2-1}(50 \mathrm{mg})$ was further fractionated on silica gel $60(100 \times 1 \mathrm{~cm}, 20 \mathrm{~g})$. Elution was performed using $n$-hex. : EtOAC isocratic mixture (1\%, $\left.500 \mathrm{~mL}, \mathrm{FR} 3 \mathrm{~mL} \mathrm{~min}^{-1}\right)$ to afford compound 17 (20 mg). Subsubfractions $\mathrm{I}_{2-2}$, and $\mathrm{II}_{2-4}\left(70,30 \mathrm{mg}\right.$ each) was further fractionated on C-18 RP-HPLC using $\mathrm{H}_{2} \mathrm{O}-\mathrm{CH}_{3} \mathrm{CN}(10-60 \%, 30 \mathrm{~min}, 5 \mathrm{~mL} / \mathrm{min})$ to afford compound 12 (20 mg), 13 (10 mg), 14 (10 mg), $15(7 \mathrm{mg})$. Sub-subfraction $\mathrm{I}_{2-3}(100 \mathrm{mg})$ was further fractionated on silica gel 60 (100 × $\left.1 \mathrm{~cm}, 20 \mathrm{~g}\right)$. Elution was performed using $n$-hex. : EtOAC isocratic mixture $\left(5 \%, 500 \mathrm{~mL}, \mathrm{FR} 3 \mathrm{~mL} \mathrm{~min}{ }^{-1}\right)$ to afford compound $16(50 \mathrm{mg})$. Finally, subfraction $\mathrm{I}_{3}$ was further fractionated on silica gel $60(100 \times 1 \mathrm{~cm}, 20 \mathrm{~g})$. Elution was performed using $n$-hex. : EtOAC isocratic mixture $\left(1 \%, 500 \mathrm{~mL}, \mathrm{FR} 3 \mathrm{~mL} \mathrm{~min}^{-1}\right)$ to afford compound 20 (30 mg). Fraction II ( $1.5 \mathrm{~g}$ ) was subjected to normal VLC fractionation on a silica gel (column $6 \times 30 \mathrm{~cm}, 50 \mathrm{~g}$ ). Elution was performed using DCM : MeOH gradient mixtures in the order of increasing polarities $(0,5,10,15,20,25,30,35,40,45,50,60,80$ and $100 \%, 1 \mathrm{~L}$ each). The effluents were collected in fractions (100 $\mathrm{mL}$ each); each fraction was concentrated and monitored by TLC using the system DCM : MeOH 9.5 : 0.5 and PAA reagent. Similar fractions were grouped and concentrated under reduced pressure to provide two sub-fractions $\left(\mathrm{II}_{1}-\mathrm{II}_{2}\right)$, which were further purified on a Sephadex $\mathrm{LH}_{20} \mathrm{Column}(0.25-0.1 \mathrm{~mm}, 100 \times 0.5$ $\mathrm{cm}, 100 \mathrm{gm}$ ) which eluted with $\mathrm{MeOH}$ to afford compound 18 (16 mg), and 19 (6 mg), separately.

Crystallization of fractions IV was performed separately using $\mathrm{CH}_{2} \mathrm{CL}_{2}$, and afforded compounds $21(2 \mathrm{~g})$.

4-(1-(4,7,11-pentadecenyl)-o-cresol (12): Yellow oil; [UV (MeOH) $\lambda_{\max }\left(\log _{\varepsilon}\right) 225$ (5.5), 260 (6.0), 300 (4.5) nm; IR U max $(\mathrm{KBr})$ 3429, 3100, 3000, 1680, 1600, 1475, 1450, 1300, 835, $601 \mathrm{~cm}^{-1}$; NMR data; see Table 1; HRESIMS m/z $314.2607[\mathrm{M}+\mathrm{H}]^{+}$(calc. for $\mathrm{C}_{22} \mathrm{H}_{34} \mathrm{O}, 314.2604$ ).

4-(1-(4,7,11-pentadecenyl)-m-cresol (13): Yellow oil; UV (MeOH) $\lambda_{\max }\left(\log _{\varepsilon}\right) 225$ (5.5), 260 (6.0), 300 (4.5) nm; IR U max $(\mathrm{KBr})$ 3429, 3100, 3000, 1680, 1600, 1475, 1450, 1300, 835, $601 \mathrm{~cm}^{-1}$; NMR data; see Table 1; HRESIMS m/z $314.2609\left[\mathrm{M}+\mathrm{H}^{+}\right.$(calc. for $\mathrm{C}_{22} \mathrm{H}_{34} \mathrm{O}, 314.2604$ ).

\section{Antiproliferative assay}

The antiproliferative activity of the isolated compounds 12-21 was measured by the sulphorhodamine B (SRB) assay as described by Skehan et al. 199034, and Vichai and Kirtikara $2006^{35}$, on breast (MCF-7), liver (HepG2) and colorectal (CACO2) cancer cell lines. Cells were seeded in 96-well microtiter plates at initial concentration of $3 \times 10^{3}$ cell/well in $150 \mu \mathrm{L}$, fresh medium and left for $24 \mathrm{~h}$ to attach to the plates. Different concentrations $0,5,12.5,25,50 \mu \mathrm{g} / \mathrm{mL}$ of the respective compound were added. The plates were incubated for $48 \mathrm{~h}$. The cells were fixed with $50 \mu \mathrm{L}$ cold trichloroacetic acid (10\% final concentration) for $1 \mathrm{~h}$ at $4^{\circ} \mathrm{C}$. The plates were washed with distilled water (automatic washer Tecan, Germany) and stained with $50 \mu \mathrm{L} 0.4 \%$ SRB dissolved in $1 \%$ acetic acid for 30 min., at room temperature. Then they were washed with $1 \%$ acetic acid and air-dried. The dye was solubilized with $100 \mu \mathrm{L} /$ well of $10 \mathrm{M}$ trisbase (pH 10.5$)$. The optical density of each well was measured spectrophotometrically at 570nm using an ELISA microplate reader (Sunrise Tecan reader, Germany). Doxorubicin was used as a positive control. The mean background absorbance's was automatically subtracted and mean values of each drug concentration were calculated. The experiment was repeated three times, and then the $\mathrm{IC}_{50}$ values were calculated.

\section{Lipoxygenase (LOXs) inhibition assay}

The ability of the isolated compounds $12-13,19$ to inhibit 5-LOX and 15-LOX enzymes $\left(\mathrm{IC}_{50}\right.$ and $K_{\mathrm{i}}$ values, $\left.\mu \mathrm{M}\right)$ was determined using human recombinant enzyme assay kits (catalogue no 60402 and 10011263 , Cayman Chemical, Ann Arbor, MI, USA) following manufacturer's specifications ${ }^{36}$. Stock solutions were freshly prepared before use and buffer solution $(0.1 \mathrm{M}$ Tris $\mathrm{HCl}, \mathrm{PH}, 7.4)$ was used. $10 \mu \mathrm{L}$ of each compound were prepared, dissolved in the least amount of DMSO and diluted with the stock solution to be in concentrations of $(0.001,0.1,1,5,10 \mu \mathrm{M})$ in a final volume of $210 \mathrm{~mL}$. The kinetic parameters for both 5 LOX and 15-LOX were determined by measuring the increase in absorbance at 238nm in an Agilent 8453 Diode Array Spectrophotometer (Agilent Technologies, Santa Clara, CA, USA). Substrate concentration was ranged from 5 to $50 \mu \mathrm{M}$. Substrate concentrations $(5,10,20,30,40,50 \mu \mathrm{M})$ were monitored in triplicate for each sample ${ }^{37}$. Doxorubicin was used as a positive control.

\section{Docking study}

The crystal structures of both 5-LOX and 15-LOX (PDB: 6N2W and 4NRE) were used for the docking analysis using Autodock Vina docking machine ${ }^{38}$. The cocrystallized ligands nordihydroguaiaretic acid (NDGA) and AA were used to determine the binding sites. The ligand to binding site shape matching root mean 
square (RMSD) threshold was set to 2.0 A. The interaction energies were determined using the Charmm Force Field (v.1.02) with 10.0A as a non-bonded cutoff distance and distance dependent dielectric. Then, 5.0A was set as an energy grid extending from the binding site ${ }^{39}$. The tested compounds were energy minimized inside the selected binding pocket. The editing and visualization of the generated binding poses were performed using Pymol software ${ }^{40}$.

\section{Molecular Dynamic Simulation}

Molecular dynamic simulations (MDS) for ligand enzyme complexes were performed according the previous protocol ${ }^{41}$, using the Nanoscale Molecular Dynamics (NAMD) 2.6 software ${ }^{42}$, applying the CHARMM27 force field ${ }^{43}$. Hydrogen atoms were added to the protein structures using the psfgen plugin included in the Visual Molecular Dynamic (VMD) 1.9 software $^{44}$. Afterward, the whole systems were solvated using TIP3P water particles and 0.15M NaCl. The energy of the generated systems was firstly minimized and gradually heated to $300 \mathrm{~K}$ and equilibrated for $200 /$ seconds. Subsequently, the MDS was continued for $20 \mathrm{~ns}$, and the trajectory was stored every $0.1 \mathrm{~ns}$ and further analyzed with the VMD 1.9 software. The MDS output were sampled every $0.1 \mathrm{~ns}$ to evaluate the conformational changes of the entire system to analyze the root mean square deviation (RMSD) and root mean square fluctuation (RMSF). The topologies and parameters of the tested compounds were prepared using the VMD Force Field Toolkit (ffTK), and the online software Ligand Reader and Modeler (http://www.charmm-gui.org/?doc=input/ligandrm $)^{45}$. MDS-derived binding free energies $(\Delta G)$ were calculated using the free energy perturbation (FEP) method through the web-based software Absolute Ligand Binder along with MDS using NAMD software ${ }^{45,46}$. Moreover, $\Delta G$ was calculated using another web-based software utilizing neural networking in its calculations, namely KDEEP (https://www.playmolecule.org/Kdeep/) ${ }^{47}$.

\section{Statistical analysis}

All in vitro experiments were performed in triplicate. Pooled data were presented as the mean \pm standard error of the mean (SEM) of at least three independent experiments. The differences among various treatment groups were determined by ANOVA, followed by Dunnett's test using PASW Statistics ${ }^{\circledR}$ version 18 (Quarry Bay, Hong Kong). A difference of $p<0.05$ was considered statistically significant compared with a vehicle-treated control group and shown by a *symbol. The $\mathrm{IC}_{50}$ values were determined using a nonlinear regression curve fitting analysis using GraphPad Prism software version 6 (La Jolla, CA, USA).

\section{Conclusions}

In the present study, phytochemical investigation of the brown algae $S$. cinnerum with the guidance of LC-HRESIMS dereplication, afforded two new phenolic derivatives (compounds 12 and 13) together with further nine known ones. These two new compounds along with compound 19 exhibited moderate in vitro antiproliferative activity against hepatic, breast, and colorectal carcinoma cell lines (HEPG2, MCF7, and CACO2, respectively) with IC ${ }_{50}$ values ranged from $11.2 \pm 0.6$ to $21.6 \pm 1.3 \mu \mathrm{M}$. A subsequent comprehensive pharmacophore-based virtual screening was conducted to putatively figure out the molecular targets of these active compounds. Both 5-LOX and 15-LOX were found to be the most probable hits. In vitro testing results supported the preliminary virtual screenings outcomes, where both new compounds $\mathbf{1 2}$ and $\mathbf{1 3}$ showed higher selective inhibition toward 5-LOX over 15-LOX, while compound $\mathbf{1 9}$ was able to inhibit both enzymes. Additional kinetic investigations showed that the three compounds exhibit competitive inhibition of both enzymes. To get a deeper insight into the mode of interaction inside the active site of each enzyme, we conducted a series of in silico experiments (docking, MDS, and binding free energy calculations) that putatively explained the lower inhibitory activity of compounds 12 and $\mathbf{1 3}$ against 15-LOX in comparison with 5-LOX to the lack of strong $\mathrm{H}$-bond interactions inside the 15-LOX's active site. In turn, both compounds exhibited significant instability and lower binding free energy that translated eventually into weaker activity against 15-LOX. The present study shows the potential of marine natural products in providing unique metabolites with potent biological activities and highlighted the power of in silico investigations in the facilitating of drug discovery and development processes.

\section{Declarations}

Supplementary materials: The NMR data are available as supplementary data.

Author contributions: Conceptualization: URA, AHE, AMS; methodology: AHE, URA, SIA, AMS; software: AHE, URA, AMS, SIA, OMH, AM; formal analysis: AHE, URA, SIA, AMS, MA, EMM, OMH; investigation: AHE, URA, SIA, AMS, HS, KAY; resources: AHE, URA, SIA, AMS, ASA; data curation: AHE, URA, SIA, AMS, AMS; writing-original draft: AHE, AMS, URA; writing-review and editing: URA, AHE, SIA, AMS, HS, AM, MA, MMA, EMM, OMH, KAY, ASA, MA, AMS; supervision: URA, SIA; project administration: SIA; funding acquisition: SIA. All authors have read and agreed to the published version of the manuscript.

Funding: The authors extend their appreciation to the Deputyship for Research and Innovation, Ministry of Education in Saudi Arabia for funding this work through the project number 375213500 .

Acknowledgments: The authors extend their appreciation to the Deputyship for Research and Innovation, Ministry of Education in Saudi Arabia for funding this work through the project number 375213500.

Conflicts of interest: the authors declare no conflict of interest.

\section{References}

1. Guiry, M. AlgaeBase. World-wide electronic publication, National university of ireland, Galway. http://www. algaebase. org/(2010). https://ci.nii.ac.jp/naid/10028197296/

2. Yip, Z. T., Quek, R. Z. and Huang, D. Historical biogeography of the widespread macroalga Sargassum(Fucales, Phaeophyceae). ). J. Phycol. 56, 300-309 (2020). https://onlinelibrary.wiley.com/doi/full/10.1111/jpy.12945 
3. Yip, Z. T.et al. Diversity and phylogeny of Sargassum (Fucales, Phaeophyceae) in Singapore. Phytotaxa369, 200-210

(2018). https://www.mapress.com/j/pt/article/view/phytotaxa.369.3.3

4. Rushdi, M. I.et al. Pharmacological and natural products diversity of the brown algae genus Sargassum. RSC Advances10, 24951-24972

(2020). https://pubs.rsc.org/en/content/articlehtml/2020/ra/d0ra03576a

5. Yende, S. R., Harle, U. N. and Chaugule, B. B. Therapeutic potential and health benefits of Rev.8, 1

(2014). https://www.ncbi.nlm.nih.gov/pmc/articles/PMC3931196/

6. Steinhilber, D.et al. 5-lipoxygenase: underappreciated role of a pro-inflammatory enzyme in tumorigenesis. 1, 143

(2010). https://www.frontiersin.org/articles/10.3389/fphar.2010.00143/full

7. Steele, V. E.et al. Lipoxygenase inhibitors as potential cancer chemopreventives. Cancer Epidemiology and Prevention Biomarkers8, 467-483

(1999). https://cebp.aacrjournals.org/content/8/5/467.short

8. Orafaie, A., Matin, M. M. and Sadeghian, H. The importance of 15-lipoxygenase inhibitors in cancer treatment. Cancer Metastasis Rev. 37, 397-408

(2018). https://link.springer.com/article/10.1007/s10555-018-9738-9

9. Gilbert, N. C.et al. Structural and mechanistic insights into 5-lipoxygenase inhibition by natural products. Biol. 1-8

(2020). https://www.nature.com/articles/s41589-020-0544-7

10. Enomoto, M. and Kuwahara, S. Enantioselective Synthesis and Stereochemical Revision of Communiols A-C, Antibacterial 2, 4-Disubstituted Tetrahydrofurans from the Coprophilous Fungus Podospora communis. , Biotechnol., Biochem. 72, 1921-1928

(2008). https://www.sciencedirect.com/science/article/abs/pii/S0040403905015273

11. Takada, N., Watanabe, R., Suenaga, K., Yamada, K. and Uemura, D. Isolation and structures of hedaols A, B, and C, new bisnorditerpenes from a Japanese brown alga. Prod. 64, 653-655 (2001). https://pubs.acs.org/doi/abs/10.1021/np0005661

12. Yoon, W.-J.et al. Anti-inflammatory effect of sargachromanol G isolated from Sargassum siliquastrum in RAW 264.7 cells. Pharmacal Res. $35,1421-1430$ (2012). https://link.springer.com/article/10.1007/s12272-012-0812-5

13. Gerasimenko, N. and Logvinov, S. Seasonal composition of lipids, fatty acids pigments in the brown alga Sargassum pallidum: The potential for health. Open Journal of Marine Science6, 498 (2016). https://www.scirp.org/html/4-1470319_71279.htm

14. Iwashima, M.et al. Antioxidant and antiviral activities of plastoquinones from the brown alga Sargassum micracanthum, and a new chromene derivative converted from the plastoquinones. Bull. 28, 374-377 (2005). https://www.jstage.jst.go.jp/article/bpb/28/2/28_2_374/_article/-char/ja/

15. Tang, H.-F.et al. Bioactive steroids from the brown alga Sargassum carpophyllum. Asian Nat. Prod. Res. 4, 95-101

(2002). https://www.tandfonline.com/doi/abs/10.1080/10286020290027362

16. Ayyad, S.-E. N., Sowellim, S. Z., El-Hosini, M. S. and Abo-Atia, A. The structural determination of a new steroidal metabolite from the brown alga Sargassum asperifolium. Zeitschrift für Naturforschung C58, 333-336 (2003). https://www.degruyter.com/view/journals/znc/58/5-6/articlep333.xml

17. Jung, M.et al. Meroditerpenoids from the brown alga Sargassum siliquastrum. Prod. 71, 1714-1719

(2008). https://pubs.acs.org/doi/abs/10.1021/np800321y

18. Seo, Y., Park, K. E. and Nam, T. J. Isolation of a new chromene from the brown alga Sargassum thunbergii. Bulletin-Korean Chemical Society28, 1831 (2007). https://pdfs.semanticscholar.org/f01e/c3640639cecb919b1548a4f58fdb6da1e637.pdf

19. Cui, Z., Li, Y.-S., Liu, H.-B., Yuan, D. and Lu, B.-R. Sulfoglycolipid from the marine brown alga Sargassum Hemiphyllum. Asian Nat. Prod. Res. 3, 117-122 (2001). https://www.tandfonline.com/doi/abs/10.1080/10286020108041378

20. Ahamad, P., Kunhi, A. and Divakar, S. New metabolic pathway for o-cresol degradation by Pseudomonas sp. CP4 as evidenced by $1 \mathrm{H}$ NMR spectroscopic studies. World J. Microbiol. Biotechnol.17, 371-377 (2001). https://link.springer.com/article/10.1023/A:1016611702882

21. Bogan Jr, L. E. and Wolk, S. K. Synthesis of and assignment of carbon-13 NMR resonances to m-cresol novolak dimers. Macromolecules25, $161-165$ (1992). https://pubs.acs.org/doi/pdf/10.1021/ma00027a027

22. Tawfike, A. et al. New bioactive metabolites from the elicited marine sponge-derived bacterium Actinokineospora spheciospongiae AMB Express 9 , 12 (2019). https://link.springer.com/article/10.1186/s13568-018-0730-0

23. Wu, W.et al. Fibrinolytic compounds isolated from a brown alga, Sargassum fulvellum. Marine drugs7, 85-94 (2009). https://www.mdpi.com/1660$3397 / 7 / 2 / 85$

24. Stappen, I., Höfinghoff, J., Buchbauer, G. and Wolschann, P. Structure-activity relationships of sandalwood odorants: synthesis of a new campholene derivative. Commun.5, 1934578X1000500902 (2010). https://journals.sagepub.com/doi/abs/10.1177/1934578X1000500902

25. Francesconi, K. A., Edmonds, J. S., Stick, R. V., Skelton, B. W. and White, A. H. Arsenic-containing ribosides from the brown alga Sargassum lacerifolium: Xray molecular structure of 2-amino-3-[5'-deoxy-5'-(dimethylarsinoyl) ribosyloxy] propane-1-sulphonic acid. Soc., Perkin Trans. $12707-2716$ (1991). https://pubs.rsc.org/en/content/articlehtml/1991/p1/p19910002707?casa_token=q2Ok7GIrNoIAAAAA:4qqO7d_bOrGZzzjKHNXsk7IW0j5F1Wv8NGo6BWwGPCmvHuvPa3jb4Z8cNTs26Jn2yLXMV3nWm0HWa4

26. Wang, X.et al. PharmMapper 2017 update: a web server for potential drug target identification with a comprehensive target pharmacophore database. Nucleic Acids Res.45, W356-W360 (2017). https://academic.oup.com/nar/article/45/W1/W356/3791213?login=true

27. Xu, X.-M.et al. 5-Lipoxygenase contributes to the progression of hepatocellular carcinoma. Rep. 4, 1195-1200 (2011). https://www.spandidospublications.com/mmr/4/6/1195

28. Hussey, H. and Tisdale, M. Inhibition of tumour growth by lipoxygenase inhibitors. Cancer 74, 683-687

(1996). https://www.nature.com/articles/bjc1996422

Page $9 / 15$ 
29. Avis, l.et al. Five-lipoxygenase inhibitors can mediate apoptosis in human breast cancer cell lines through complex eicosanoid interactions. FASEB J. 15, 2007-2009 (2001). https://faseb.onlinelibrary.wiley.com/doi/full/10.1096/fj.00-0866fje

30. Bishayee, K. and Khuda-Bukhsh, A. R. 5-lipoxygenase antagonist therapy: a new approach towards targeted cancer chemotherapy. Acta Biochim. Biophys. Sin. 45, 709-719 (2013). https://academic.oup.com/abbs/article/45/9/709/1146?login=true

31. Cer, R. Z., Mudunuri, U., Stephens, R. and Lebeda, F. J. IC 50-to-K i: a web-based tool for converting IC 50 to K i values for inhibitors of enzyme activity and ligand binding. Nucleic Acids Res. 37, W441-W445 (2009). https://academic.oup.com/nar/article/37/suppl_2/W441/1123706?login=true

32. Ashworth, M. R. F. and Stahl, E. Thin-layer chromatography: a laboratory handbook. (Springer Science and Business Media, 2013). https://books.google.com.eg/books?hl=en\&lr=\&id=06v7CAAAQBAJ\&oi=fnd\&pg=PA1\&dq=32.\%09Ashworth,+M.R.F.\%3B+Stahl,+E.+Thinlayer+chromatography:+a+laboratory+handbook\%3B+Springer+Science+and+Business+Media:+2013\&ots=UUi3D7RewN\&sig=bkWmSFTqhRRmJ5IXwXrC

33. redir_esc=y\#v=onepage\&q=32.\%09Ashworth\%2C\%20M.R.F.\%3B\%20Stahl\%2C\%20E.\%20Thinlayer\%20chromatography $\% 3 \mathrm{~A} \% 20 \mathrm{a} \% 20$ laboratory $\% 2$ handbook\%3B\%20Springer\%20Science\%20and\%20Business $\% 20 \mathrm{Media} \% 3 \mathrm{~A} \% 202013 \& \mathrm{f}=\mathrm{false}$

34. Abdelmohsen, U. R.et al. Dereplication strategies for targeted isolation of new antitrypanosomal actinosporins $\mathrm{A}$ and $\mathrm{B}$ from a marine sponge associatedActinokineospora sp. EG49. Marine drugs12, 1220-1244 (2014). https://www.mdpi.com/1660-3397/12/3/1220

35. Skehan, P.et al. New colorimetric cytotoxicity assay for anticancer-drug screening. JNCl, J. Natl. Cancer Inst. 82, 1107-1112 (1990). https://academic.oup.com/jnci/article-abstract/82/13/1107/970741

36. Vichai, V. and Kirtikara, K. Sulforhodamine B colorimetric assay for cytotoxicity screening. 1, 1112-1116 (2006). https://www.nature.com/articles/nprot.2006.179/

37. Yamamoto, S. Mammalian lipoxygenases: molecular structures and functions. Biochimica et Biophysica Acta (BBA)-Lipids and Lipid Metabolism1128, 117-131 (1992). https://www.sciencedirect.com/science/article/abs/pii/0005276092902979

38. Mitra, S., Bartlett, S. G. and Newcomer, M. E. Identification of the substrate access portal of 5-lipoxygenase. 54, 6333-6342 (2015). https://pubs.acs.org/doi/abs/10.1021/acs.biochem.5b00930

39. Trott, O. and Olson, A. J. AutoDock Vina: improving the speed and accuracy of docking with a new scoring function, efficient optimization, and multithreading. Chem.31, 455-461 (2010). https://onlinelibrary.wiley.com/doi/full/10.1002/jcc.21334

40. Sayed, A. M.et al. Microbial natural products as potential inhibitors of SARS-CoV-2 main protease (Mpro). Microorganisms8, 970 (2020). https://www.mdpi.com/2076-2607/8/7/970

41. Lill, M. A. and Danielson, M. L. Computer-aided drug design platform using PyMOL. -Aided Mol. Des. 25, 13-19 (2011). https://link.springer.com/article/10.1007/s10822-010-9395-8

42. Alhadrami, H. A.et al. Flavonoids as Potential anti-MRSA Agents through Modulation of PBP2a: A Computational and Experimental Study. Antibiotics9, 562 (2020). https://www.mdpi.com/2079-6382/9/9/562

43. Phillips, J. C.et al. Scalable molecular dynamics with NAMD. Chem.26, 1781-1802 (2005). https://onlinelibrary.wiley.com/doi/full/10.1002/jcc.20289

44. MacKerell Jr, A. D.et al. All-atom empirical potential for molecular modeling and dynamics studies of proteins. The journal of physical chemistry B102, 3586-3616 (1998). https://pubs.acs.org/doi/abs/10.1021/jp973084f

45. Humphrey, W., Dalke, A. and Schulten, K. VMD: visual molecular dynamics. Graphics 14, 33-38

(1996). https://www.csb.pitt.edu/BBSI/2007/lectures/VMD.pdf

46. Jo, S., Kim, T., Iyer, V. G. and Im, W. CHARMM-GUI: a web-based graphical user interface for CHARMM. Chem. 29, 1859-1865

(2008). https://onlinelibrary.wiley.com/doi/full/10.1002/jcc.20945

47. Jo, S., Jiang, W., Lee, H. S., Roux, B. t. and Im, W. (ACS Publications, 2013). https://pubs.acs.org/doi/abs/10.1021/ci300505n

48. Jiménez, J., Skalic, M., Martinez-Rosell, G. and De Fabritiis, G. K deep: Protein-ligand absolute binding affinity prediction via 3d-convolutional neural networks. Inf. Model.58, 287-296 (2018). https://pubs.acs.org/doi/abs/10.1021/acs.jcim.7b00650

\section{Figures}


<smiles>CC[C@H](O)[C@H]1CC(CCCC(=O)O)CO1</smiles>

1<smiles>C/C(C=O)=C\CC/C(C)=C/CC[C@]1(C)CCc2cc(O)cc(C)c2O1</smiles>

4

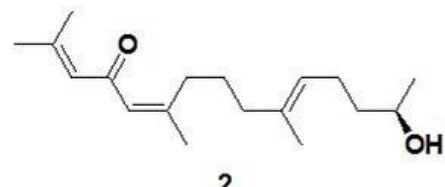

2<smiles>CCCCC=CCC=CCC=CCCCCCCCC(=O)O</smiles>

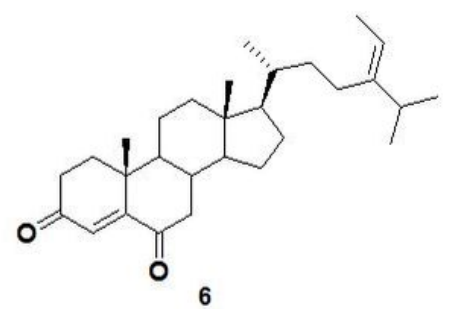

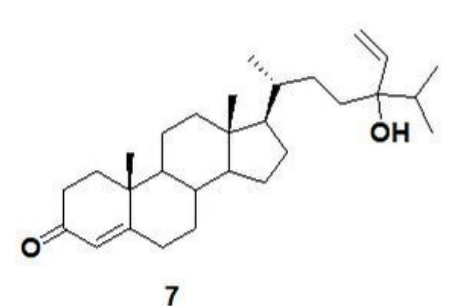

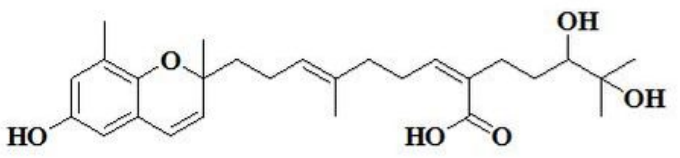

10

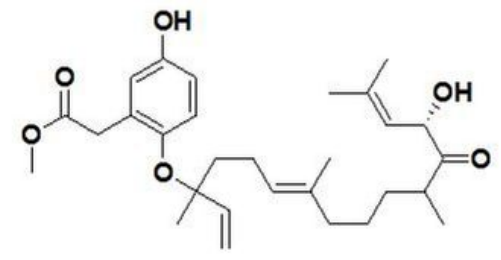

8
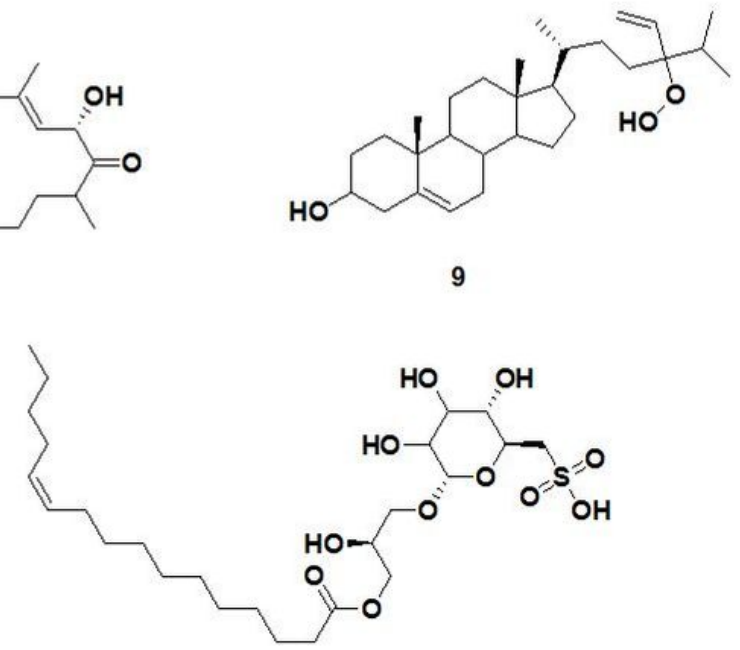

11

Figure 1

Dereplicated metabolites from LC-HRESIMS analysis of Sarragassum cinnerum 

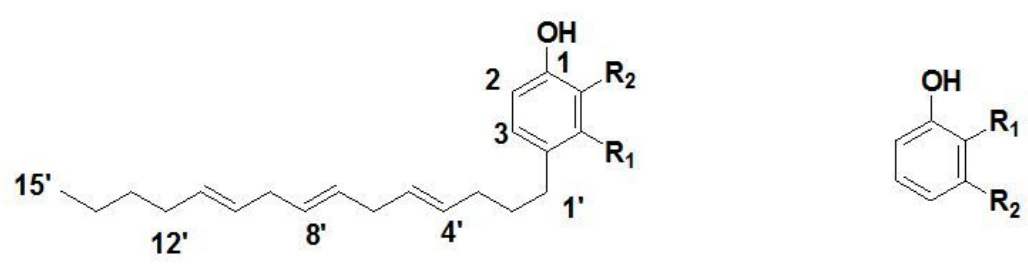

$$
\begin{array}{llllll} 
& \mathbf{R}_{\mathbf{1}} & \mathbf{R}_{\mathbf{2}} & & \mathbf{R}_{\mathbf{1}} & \mathbf{R}_{\mathbf{2}} \\
12 & -\mathrm{H} & -\mathrm{CH}_{3} & 14 & -\mathrm{H} & -\mathrm{CH}_{3} \\
13 & -\mathrm{CH}_{3} & -\mathrm{H} & 15 & -\mathrm{CH}_{3} & -\mathrm{H}
\end{array}
$$
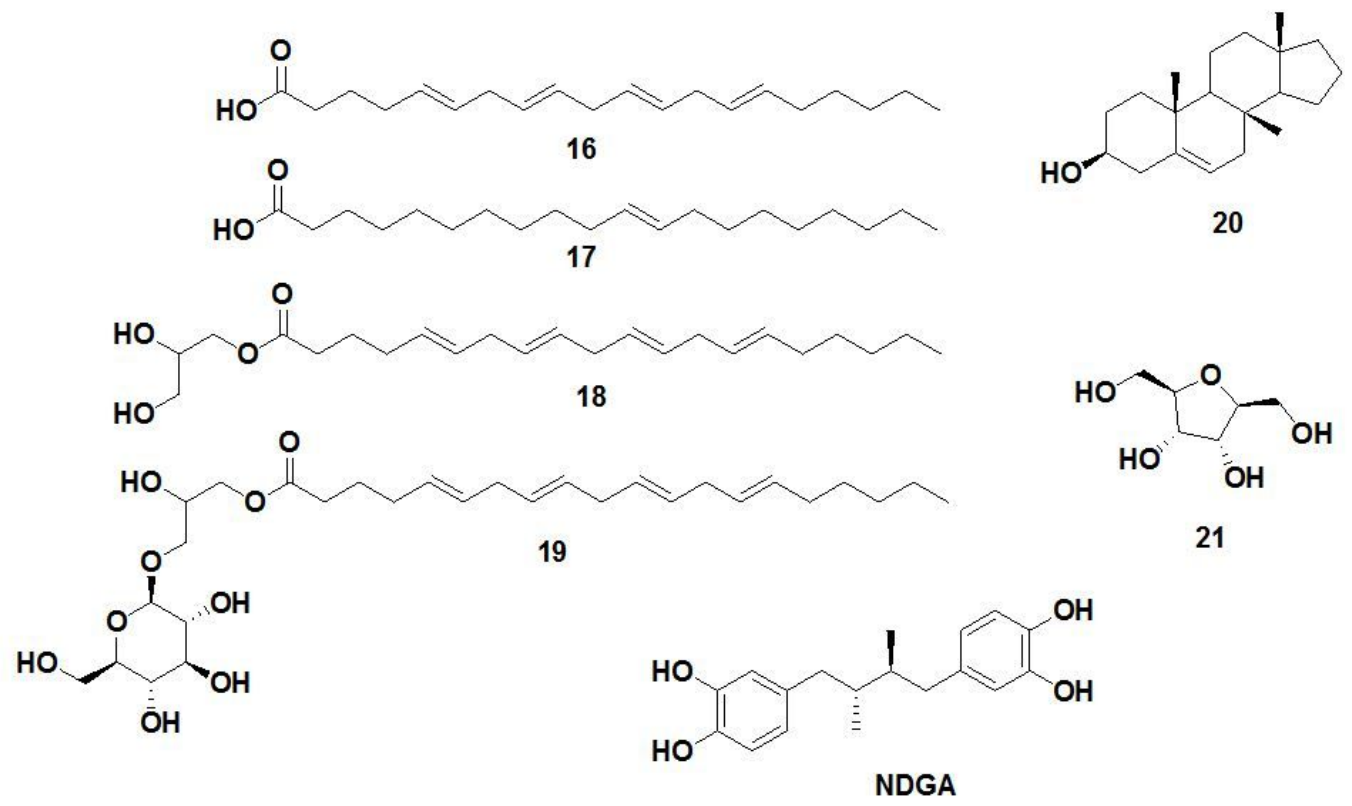

Figure 2

Structures of compounds isolated from Sarragassum cinnerum 12-21 together with 5-LOX and 15-LOX's co-crystalized ligands AA 16 and NDGA

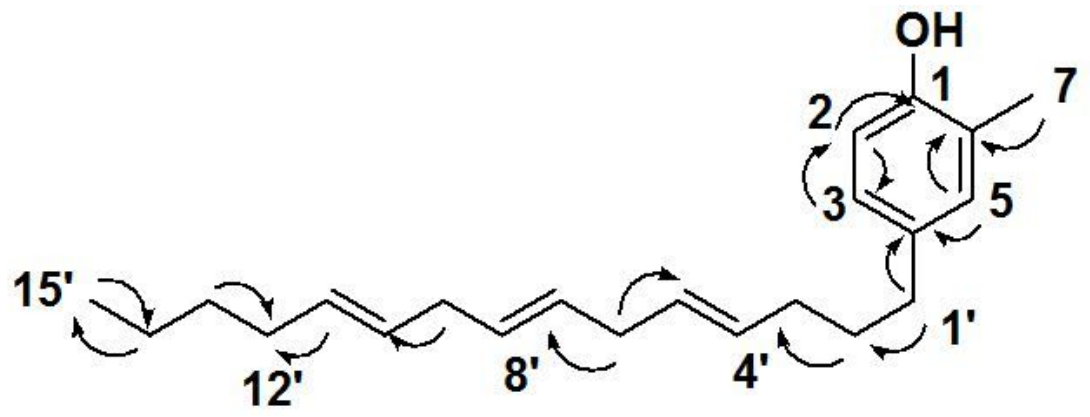

Figure 3

Selected HMBC (->) correlations of compound 12

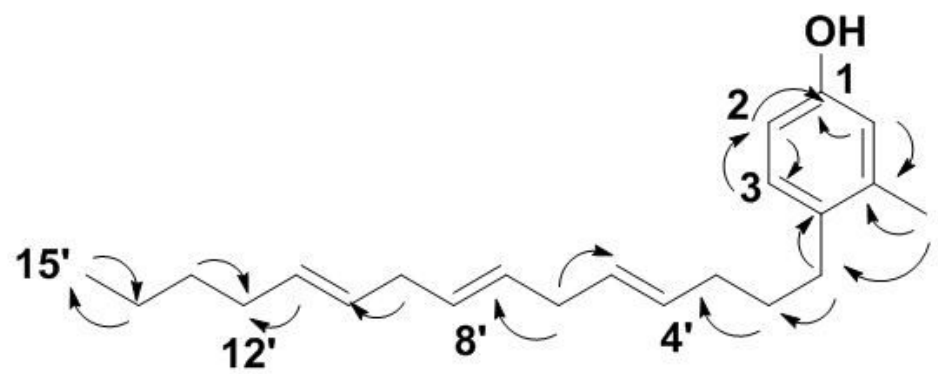


Figure 4

Selected HMBC (->) correlations of compound 13
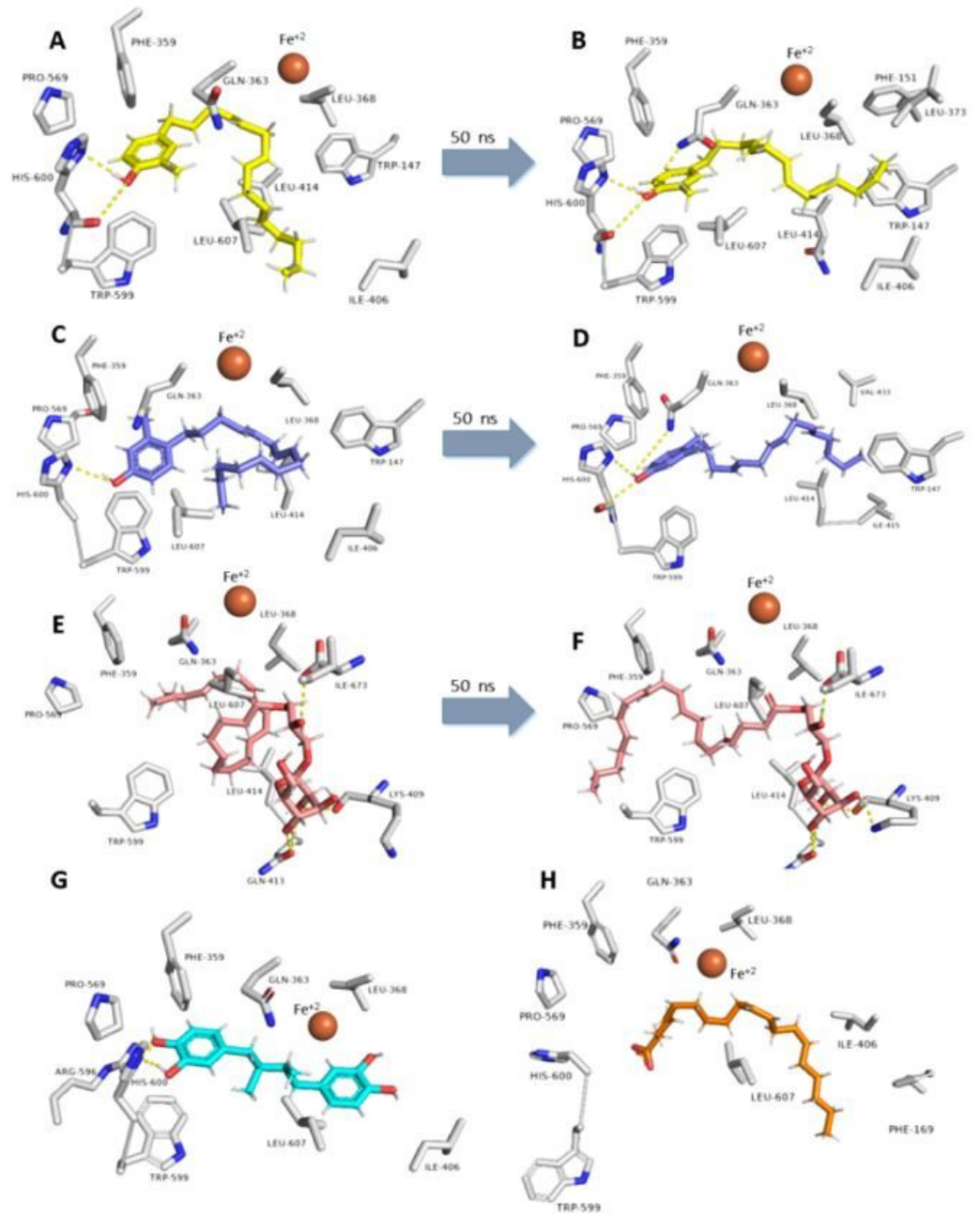

\section{Figure 5}

Binding modes of compounds 12, 13, and 19 inside 5-LOX's active site, A, C, and E: Their binding modes upon docking, B, D, and F: Their binding modes over 50 ns MDS. G and H: Binding modes of the co-crystalized ligands AA and NDGA 

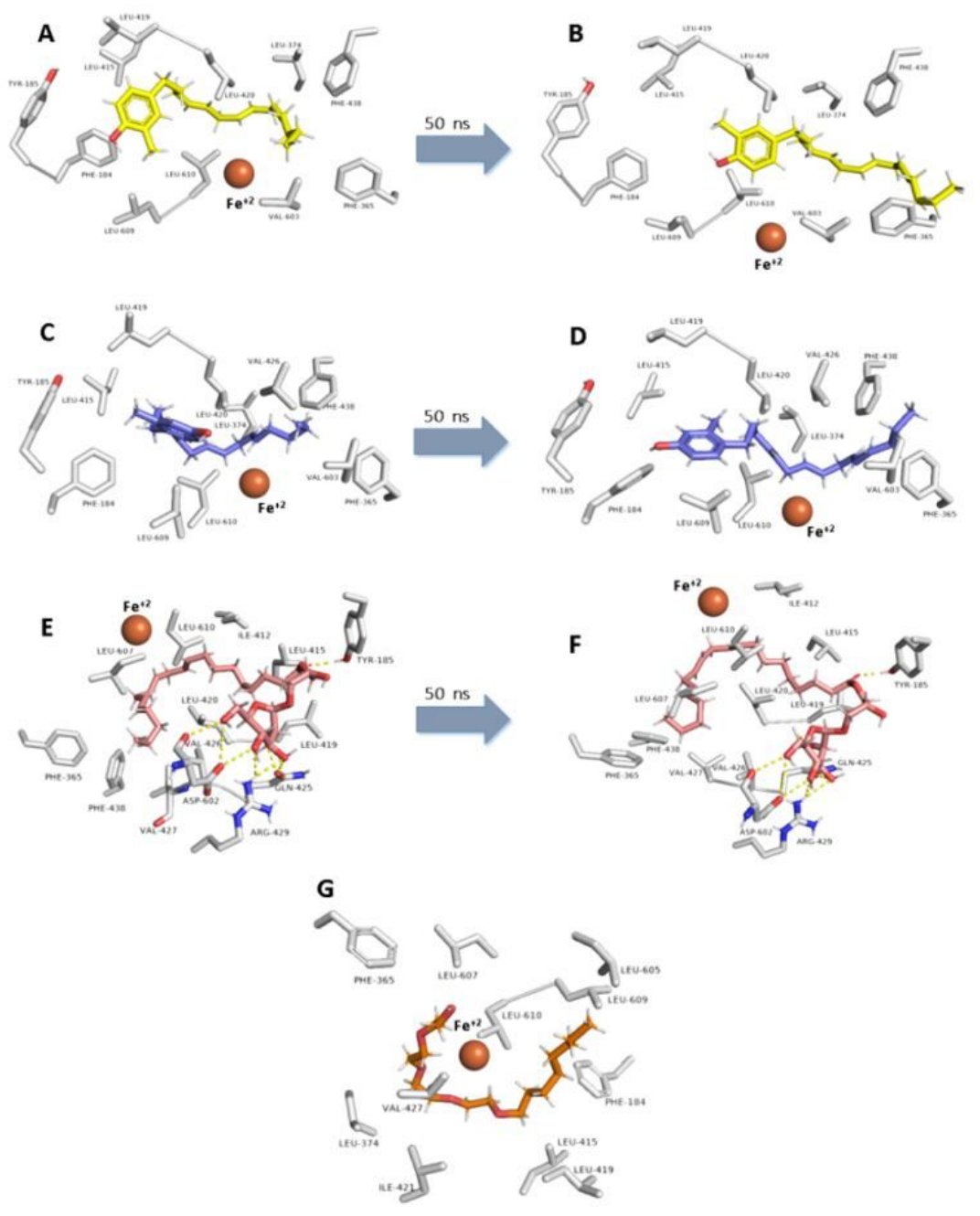

\section{Figure 6}

Binding modes of compounds 12, 13, and 19 inside 15-LOX's active site, A, C, and E: Their binding modes upon docking. B, D, and F: Their binding modes over 50 ns MDS. G and H: Binding mode of the co-crystalized ligands AA 

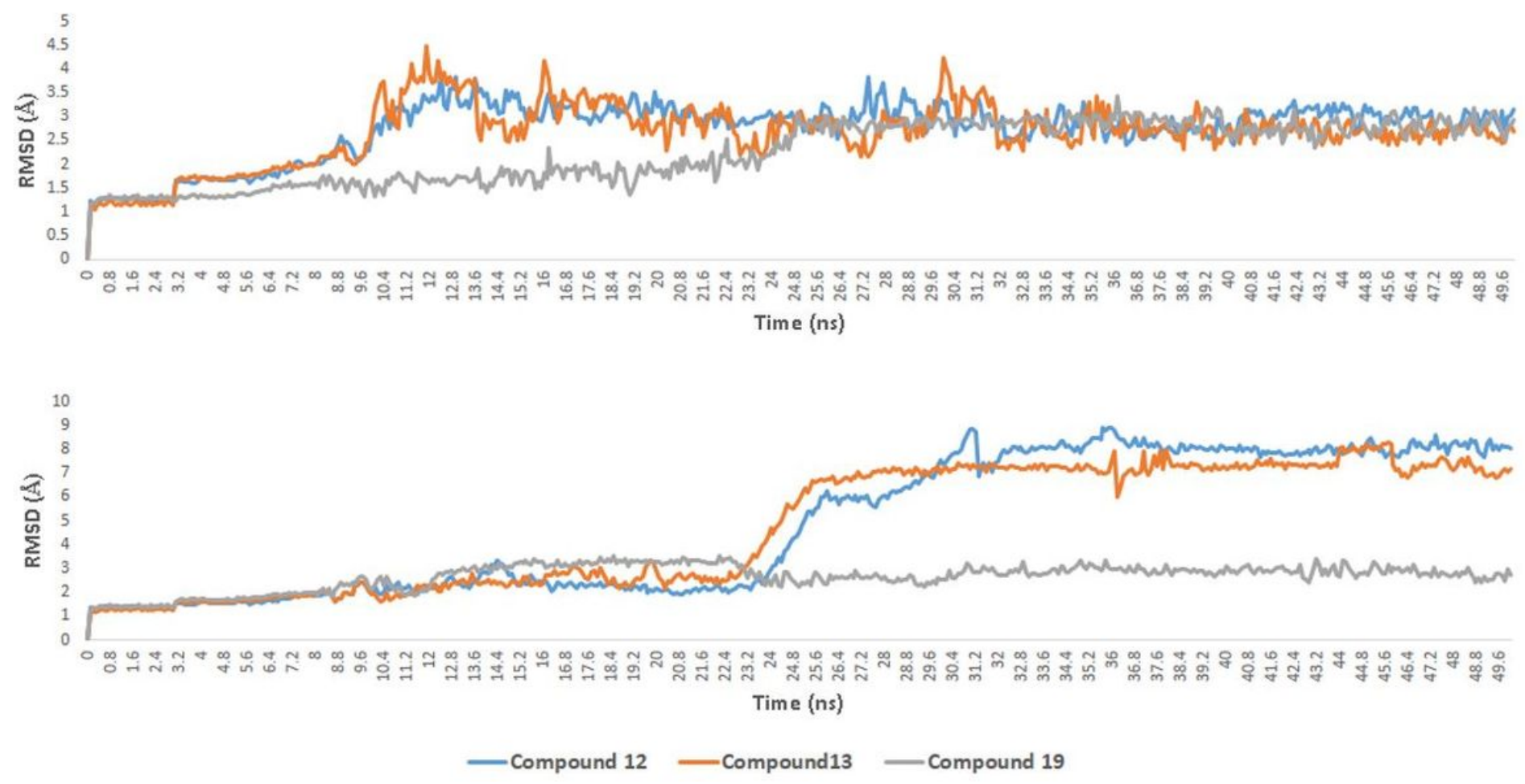

\section{Figure 7}

RMSDs of compounds 12,13 and 19 inside 5-LOX and 15-LOX's active sites over 50 ns of MDS

\section{Supplementary Files}

This is a list of supplementary files associated with this preprint. Click to download.

- suppdatasergasumcinerum.docx 